\title{
Fabrication of Hollow Microspheres Using Single Step Electrospraying Process
}

\author{
Sumeet R. Mishra ${ }^{1}$, K. Ranjith ${ }^{1}$, K.K. Khadija ${ }^{1}$ and Praveen C. Ramamurthy ${ }^{1,2,{ }^{*}}$ \\ ${ }^{1}$ Department of Materials Engineering, Indian Institute of Science, Bangalore, 560012, India \\ ${ }^{2}$ Center for Nanoscience and Engineering, Indian Institute of Science, Bangalore, 560012, India
}

\begin{abstract}
In this study, a single step method for large scale fabrication of hollow microspheres with a narrow size distribution is presented. PolyBenzoThiadiazole (PolyBT), a conducting polymer, was electrosprayed at high voltage to obtain microspheres. Hollow spheres of size ranging from 4.1 to $7.3 \mu \mathrm{m}$ were observed through scanning electron microscope images, without any chemical degradation as shown by FTIR studies. In addition, these microspheres demonstrated a change in optical and hydrophobic properties as exhibited by the UV-visible and contact angle measurements. Thus providing interesting opportunities for use in biomedical applications, sensors as well as optoelectronic devices.
\end{abstract}

Keywords: Conducting polymers, Electrospraying, Hollow microspheres, PolyBenzoThiadiazole (PolyBT).

\section{INTRODUCTION}

Polymer spheres of submicron size are being extensively studied for drug delivery systems [1]. The hollow structure of these spheres allows the target molecules to be incorporated within, for controlled release at a later stage. Polymeric microspheres are also used as sensors [2], ion-sensors [3,4], pH sensors[5], sensors for explosives tracing [6] and bulk ion optodes [7]. Recently, molecular imprinted microspheres (MIM) used as a chemiluminiscence sensor showed high sensitivity and selectivity [8]. In addition, use of polymeric microspheres as a buffer for expansion in lithium rechargeable batteries has improved the cycle performance of the anode [9].

Polymer nanospheres have been synthesized by several techniques like microemulsion polymerization [10], in situ polymerization using a magnetic ionic liquid [11] oxidative polymerization [12,13], and coretemplate-free routes $[14,15]$. Recently, nanorods and microspheres of a conducting polymer polyindole were reported by interfacial polymerization via micelle formation [16]. Pulsed sonoelectrochemical method, employing a combination of sonic and electric pulses, was used to obtain conducting polymer microspheres in range of 1-3 $\mu \mathrm{m}$ [17] Submicron sized spheres of poly $\mathrm{N}$-methylaniline (PNMA), for use as antibacterial coatings [18],was obtained by template-free polymerization [19]. Several other routes for obtaining conducting polymer microspheres, like template-free synthesis of polypyrrole microspheres [13], transition

*Address correspondence to this author at the Department of Materials Engineering, Center for Nanoscience and Engineering, Indian Institute of Science, Bangalore, 560012, India; Tel: +91-80-2293-2627;

Fax: 91-080-2360-0472; E-mail: onegroupb203@gmail.com metal assisted oxidative dispersion polymerization route for size-controlled polythiophene microspheres [20], were also reported. A brief summary of the various available techniques for polymeric nanosphere synthesis were reported by W. Meier et al. [21]. However fabrication of conducting polymer microspheres using electrospraying, a comparatively straightforward technique, has not been explored.

Electrospraying, or electro hydrodynamic atomization, is a technique to get submicron spheres, has the same principle as electrospinning. A minimum solution concentration is required for electrospinning, below which electrospraying occurs. This transition from electrospinning to electrospraying can be explained on the basis of chain entanglement density. Studies were carried out to associate electrosprayability with the molecular weight, entanglement number and the concentration of various polymer/ solvent systems [22]. Electrospraying consists of a syringe needle, connected to high voltage of the order of few $\mathrm{kV}$ and a grounded collector. The forced liquid through the needle encounters electrical forces and breaks into a number of droplets. The size of droplets may vary from 6-8 micrometers down to $50-80$ nanometers with generally a narrow size distribution. The size of the droplets can be controlled by parameters like flow rate of the solution, applied voltage, viscosity, and needle orifice size $[23,24]$. This coupled with the high deposition efficiency, low tendency for agglomeration and the control on the direction of deposition associated with electrospraying makes it an important process in field of nanotechnology. The importance of electrospraying in formation of polymeric microspheres was also demonstrated [25-27] using coaxial electrospraying of 
polyethersulfone hollow microspheres with an additional step to remove core solvent was reported [28].

In the present study, electrospraying of a conducting polymer, PolyBenzoThiadiazole (polyBT) to obtain hollow micro-sized spheres are reported and its properties were studied using SEM, FTIR, UV and contact angle measurement.

\section{EXPERIMENTAL}

\subsection{Materials}

O-phenylenediamine, triethylaminethionyl chloride, bis(1,5-cyclooctadiene) nickel(0)(Ni(COD)2), 2,2'bipyridine and 1,5-cyclooctadiene were purchased from Sigma-Aldrich and used without further purification. Dimethyl formamide (DMF), hydrobromic acid (assay $48 \%$ ), bromine and chloroform were procured from local suppliers and were purified before use.

\subsection{PolyBT Synthesis}

PolyBT was synthesized by the Yamamoto coupling polymerization of the dibrominated monomer [29]. 2,1,3-benzothiadiazole was synthesized from Ophenylenediamine in the presence of triethylamine and thionyl chloride. 4,7-dibromo-2,1,3-benzothiadiazole was obtained by the bromination of 2,1,3benzothiadiazole in the presence of bromine and hydrobromic acid [30]. Polymerization was carried out by Yamamoto coupling reaction in presence of bis(1,5cyclooctadiene)nickel(0)(Ni(COD) $\left.)_{2}\right), 2,2$ '-bipyridine and 1,5-cyclooctadiene in dry DMF. Weight average molecular weight and the average hydrodynamic radius of the synthesized polymer was determined to be $3.7 \times 10^{-7} \mathrm{~g} / \mathrm{mol}$ and $784 \mathrm{~nm}$ respectively by dynamic light scattering technique.

\subsection{Electrospraying}

As-synthesized $40 \mathrm{mg}$ of polyBT in $4 \mathrm{~mL}$ of chloroform was magnetically stirred for $4 \mathrm{~h}$ to get a consistent solution before electrospraying. Electrospraying setup consists of a high voltage source (latome Electric (I) Pvt. Ltd) with maximum output of 20 $\mathrm{kV}$. A precision controlled infusion pump (Holmarc SPLF-2D) and an aluminum flat plate collector (15 × 15 $\mathrm{cm})$. An aluminum foil was covered on the collector to facilitate the removal of samples. Electrospraying was carried out at an applied voltage of $10 \mathrm{kV}$ and a tip-tocollector distance of $7 \mathrm{~cm}$. Solution was supplied through needle (gauge no 22; ID: $0.39 \mathrm{~mm}$ ) attach onto a $1 \mathrm{~mL}$ syringe at a constant flow rate of $200 \mu \mathrm{L} / \mathrm{min}$ for 150 seconds.

\subsection{Characterization}

To observe the electrosprayed morphology of polyBT, samples were mounted on the stub using a double sided carbon tape. Samples were then gold coated using JEOL JFC-1100E ion sputtering device. Scanning electron microscopy using FEl-Quanta 200 and field emission scanning electron microscopy by FEI-SIRION were then carried out at an accelerating voltage of $5 \mathrm{kV}$. Fourier transform infrared spectroscopy (FTIR) in ATR mode was carried out for polyBT powder and the electrosprayed polyBT spheres using Thermo-Nicolet 6700 spectrometer in the wave number range of $4000-400 \mathrm{~cm}^{-1}$ with a resolution of $1 / 2$ $\mathrm{cm}^{-1}$ to ensure sample composition after electrospraying. UV-visible absorption characteristics using analytikjena SPECORD S-600 in wavelength range 200-1000 nm were carried out to study the optical properties for both the samples, as synthesized polyBT and the powder of electrosprayed polyBT. The static contact angle measurements of the drop cast and electrosprayed material were carried out $\left(22^{\circ} \mathrm{C}\right)$ in an OCA 30 commercial goniometer (Dataphysics, Germany) containing stepper motor for controlling the volume $(3 \mu \mathrm{L})$ of the liquid (millipore water) supplied from a microsyringe.

\section{RESULTS AND DISCUSSION}

Scanning electron micrographs of electrosprayed polyBT are shown in Figure 1. PolyBT was observed in the form of spheres with the mean diameter of $5.5 \mu \mathrm{m}$ with about 75 percent of spheres in the range of 4.1 to 7.3 $\mu \mathrm{m}$ (Figure 2). The spheres are found to be uniformly distributed covering more than 80 percent of the deposition area without coalescing (Figures 1a and 1b). The high voltage employed during electrospraying induces surface charges onto the spheres preventing coalescence and allowing the molecules to maintain spherical geometry (Figures 1c and 1d) [31]. Furthermore, a multitude of spheres are observed to be broken due to the sudden impact of hitting the collector plate (Figure 1c), also a closer look at microspheres indicates that the spheres are hollow; caused by solvent escaping. This non-coalescencing property could be explored to create standalone polyBT spheres hence finding application in several biomedical and sensor applications.

Normalized UV-visible spectra of synthesized and electrosprayed polyBT are as shown in Figure 3. 

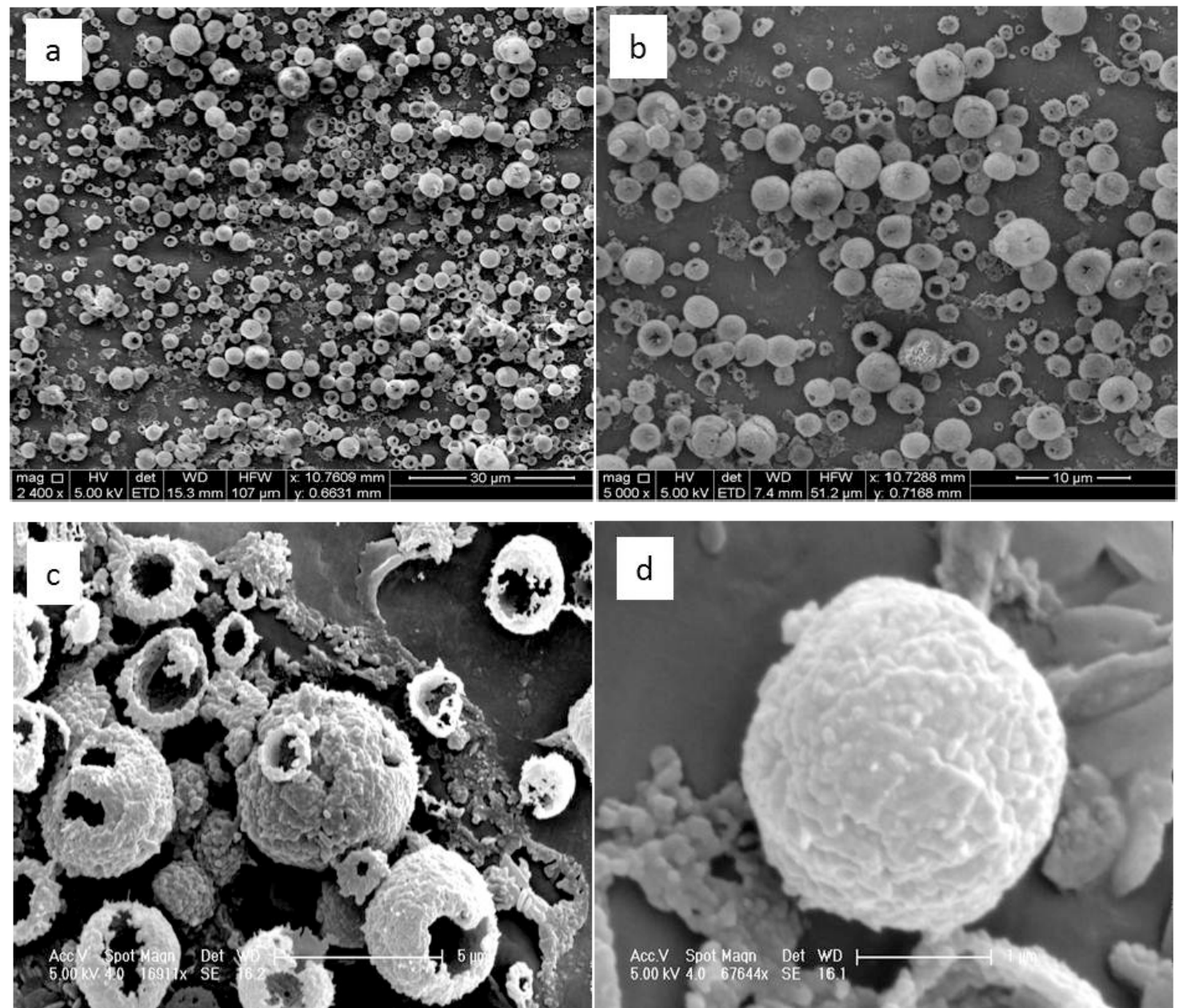

Figure 1: a-d). Scanning electron micrographs of electrosprayed polyBT microspheres.

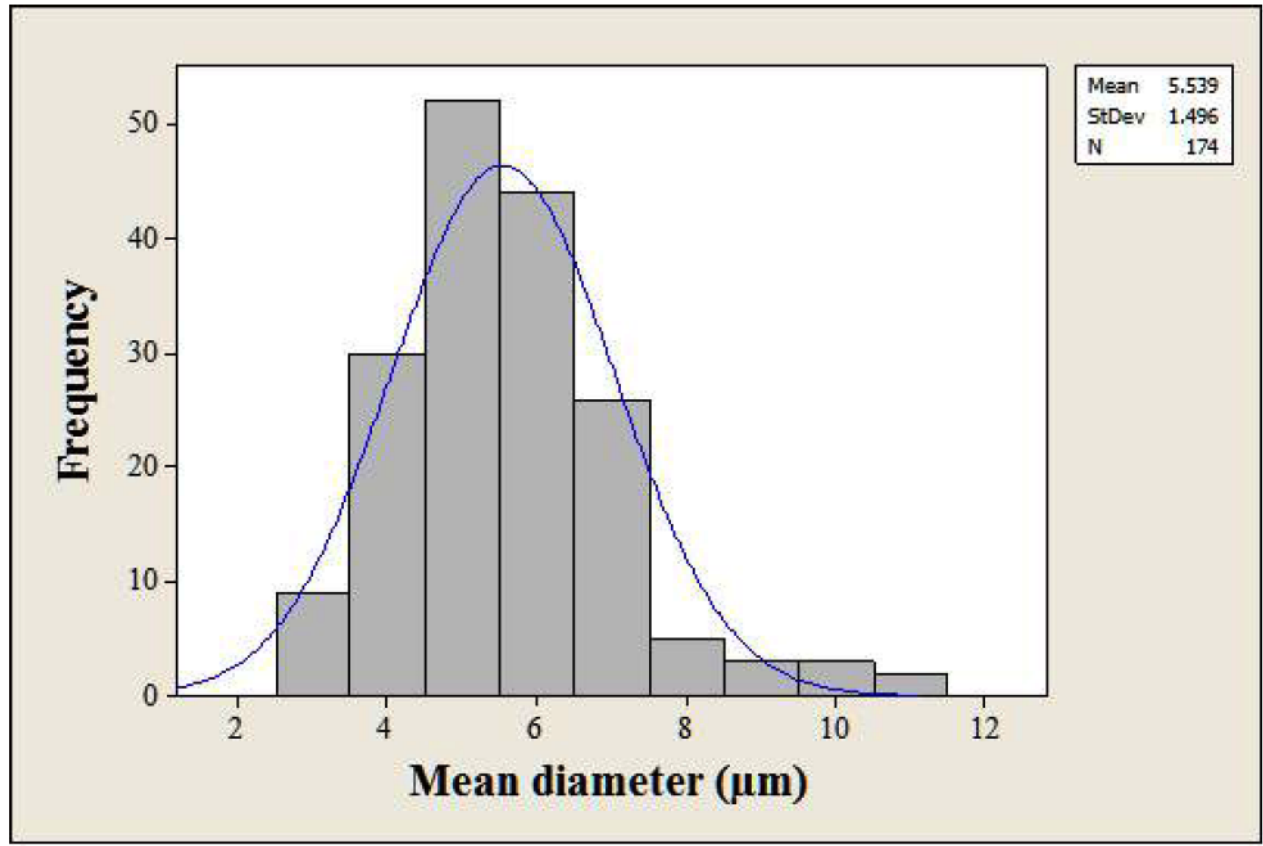

Figure 2: Histogram of polyBT microspheres diameter. 


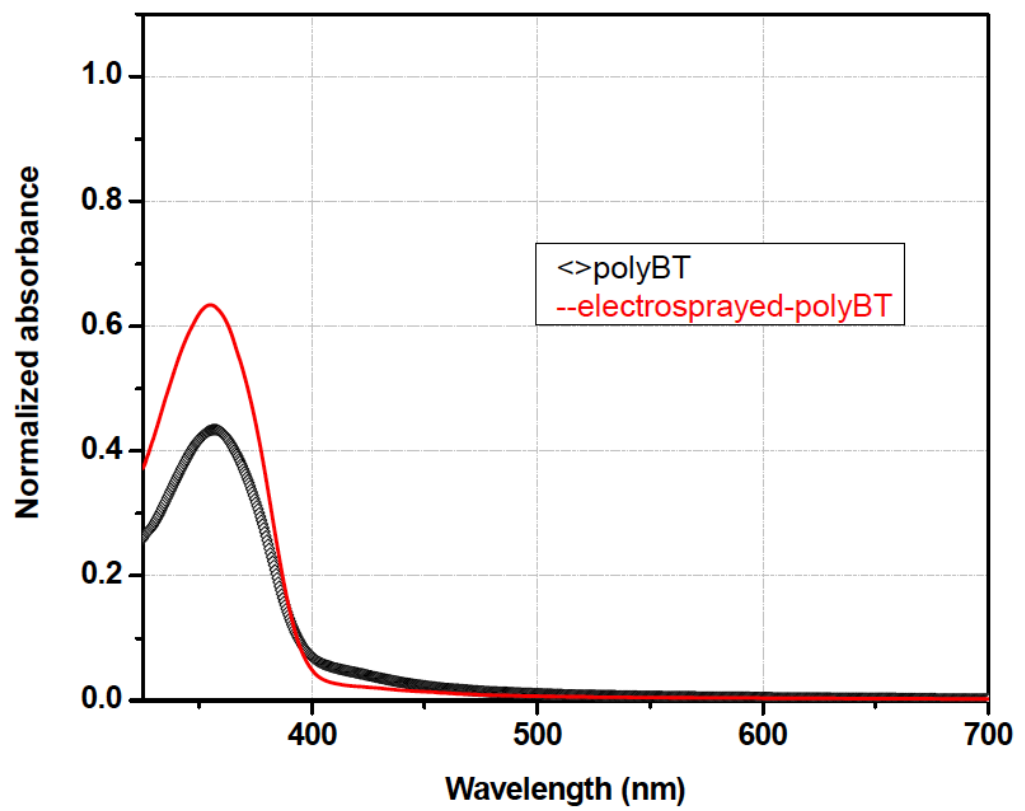

Figure 3: UV-visible spectra for as synthesized and electrosprayed polyBT.

Absorption onset for polyBT sample occurred at $\sim 512$ $\mathrm{nm}$ and corresponding band gap was determined as $2.42 \mathrm{eV}$. Electrosprayed polyBT showed absorption onset at $485 \mathrm{~nm}$ with corresponding band gap of 2.55 $\mathrm{eV}$. A red shift of $27 \mathrm{~nm}$ is observed in the onset of absorption for electrosprayed polyBT compared to as synthesized polyBT indicating increased molecular ordering. An absorption maximum was observed to remain same before and after electrospinning at $\sim 353$ $\mathrm{nm}$. Hence spectra suggest that the electrosprayed polyBT microspheres have higher absorbance than synthesized polyBT.

FTIR spectra of both the samples are shown in Figure 4. In the spectrum of synthesized polyBT, it was observed that $3042 \mathrm{~cm}^{-1}$ peak corresponds to $\left(C^{\prime} R^{\prime \prime}=\right.$ $\mathrm{CHR}$ group) $\mathrm{CH}$ stretching, whereas $2969 \mathrm{~cm}^{-1}$ relates to (R-CH3 group) $\mathrm{CH}$ asymmetrical stretching and $2861 \mathrm{~cm}^{-1}$ corresponds to $\left(\mathrm{R}-\mathrm{CH}_{3}\right.$ group) $\mathrm{CH}$

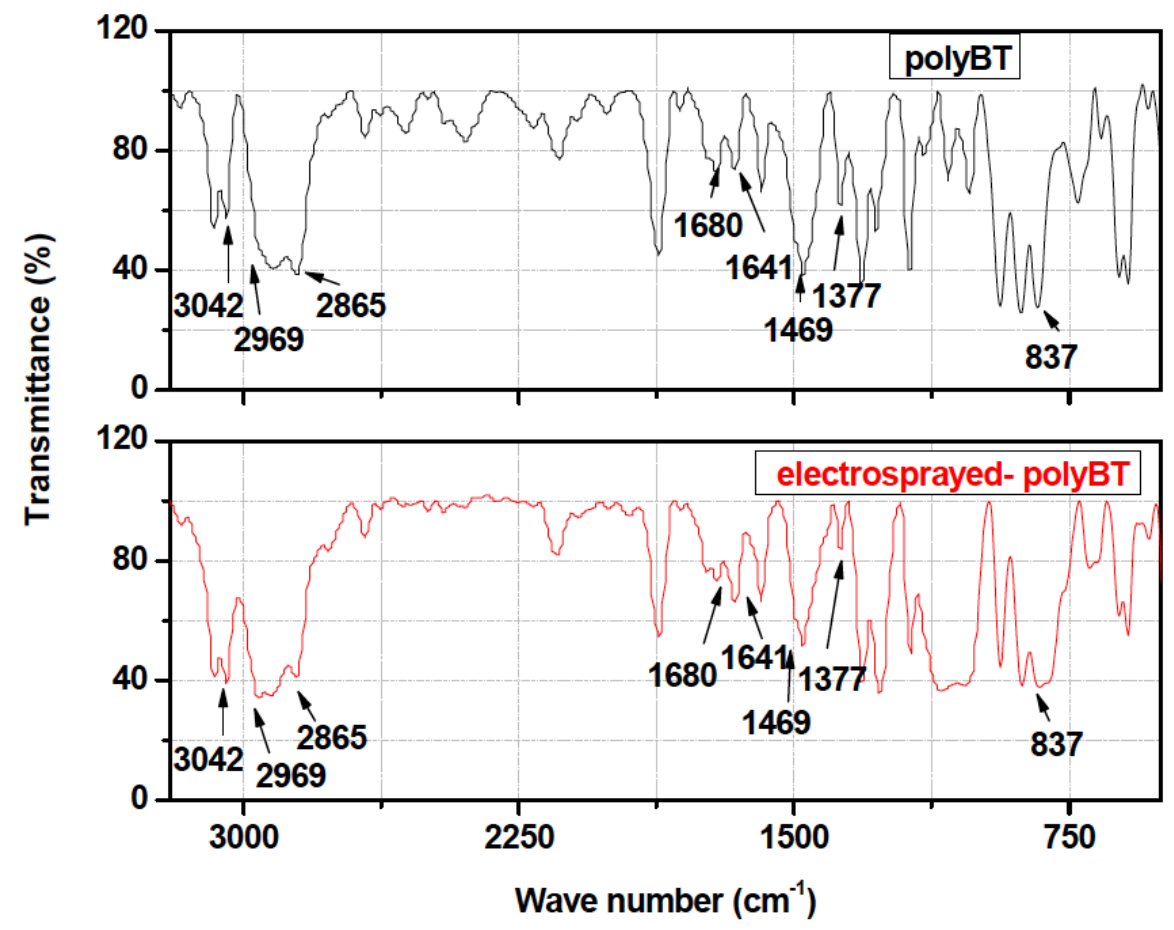

Figure 4: FTIR spectra for as synthesized and electrosprayed polyBT. 
symmetrical stretching, both are merged to be observed as a broad strong peak. A strong peak is seen at $1469 \mathrm{~cm}^{-1}$, associated to $\left(\mathrm{R}-\mathrm{CH}_{3}\right.$ group) $\mathrm{CH}$ asymmetric deformation and peak at $1377 \mathrm{~cm}^{-1}$ relates to (R-CH3 group), $\mathrm{CH}$ symmetric deformation. Weak peaks at $1680 \mathrm{~cm}^{-1}$ appeared for $\left(C R^{\prime} R^{\prime \prime}=C H R\right.$ group) $\mathrm{CC}$ stretching and $1641 \mathrm{~cm}^{-1}$ corresponds to $(\mathrm{C}=\mathrm{CH}-$ $\mathrm{CH}=\mathrm{C}$ group) $\mathrm{CH}$ stretching [32]. These characteristic peaks are also observed in electrosprayed polyBT as seen in Figure 4. These results indicate that the absence of any material degradation or bond breaking due to applied high voltage during electrospraying.

Contact angle for electrosprayed polyBT was found to be $120.68 \pm 9.25$ and that of synthesized polyBT was $98.99 \pm 5.65$ (Figure 5). This increase in the hydrophobicity of the polyBT film can be attributed to morphological change that occurs due to electrospraying; the presence of microspheres prevents the spreading of the liquid drop resulting in increase in the contact angle.

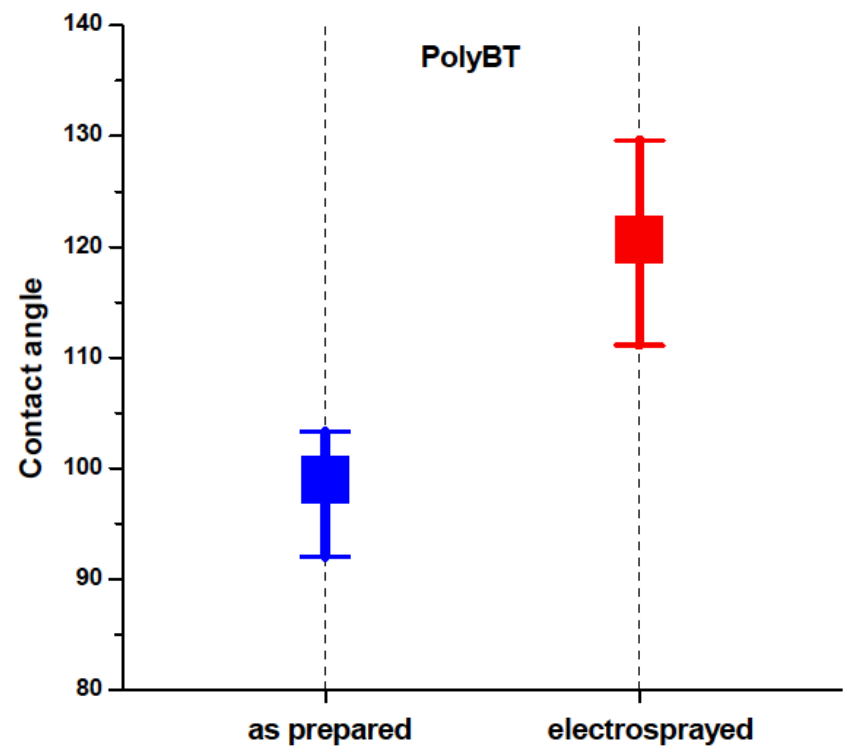

Figure 5: Contact angle measurements for as synthesized and electrosprayed polyBT.

\section{CONCLUSION}

Poly BT a conducting polymer, synthesized in lab, was for the first time electrosprayed to obtain hollow microspheres in the range of 4.1 to $7.3 \mu \mathrm{m}$. FTIR results indicate the chemical integrity of the polymer even after electrospraying process. In addition, it was observed that microspheres exhibited remarkable difference from synthesized polyBT in terms of their optical properties and hydrophobicity. Furthermore, electrospraying thus enables to deposit microsphere on large scale, hence can be potentially suitable route for sensor fabrication as well as drug delivery applications.

\section{ACKNOWLEDGEMENTS}

The authors acknowledge the Institute Nano Science Initiative (INI) and Indian Institute of Science, Bangalore. In addition the authors gratefully acknowledge Prof. Rajeev Ranjan and Ms. Rohini Garg of Department of Materials Engineering, Indian Institute of Science, and Bangalore for high voltage source.

\section{REFERENCES}

[1] Reyderman L, Stavchansky S. Electrostatic spraying. Int J Pharm 1995; 124: 75-85. http://dx.doi.org/10.1016/0378-5173(95)00078-W

[2] Kumaraswamy S, Bergstedt T, Shi X, et al. Fluorescent. Proc Natl Acad Sci USA 2004; 101: 7511-5 http://dx.doi.org/10.1073/pnas.0402367101

[3] Méallet-Renault R, Denjean P, Pansu R. Polymer beads. Sens Actuators B Chem 1999; 59: 108-12. http://dx.doi.org/10.1016/S0925-4005(99)00205-1

[4] Telting-Diaz M, Bakker E. Mass-Produced. Anal Chem 2002; 74: 5251-6. http://dx.doi.org/10.1021/ac025596i

[5] Déjugnat C, Sukhorukov GB. pH-Responsive. Langmuir 2004; 20: 7265-9. http://dx.doi.org/10.1021/la049706n

[6] Fletcher RA, Brazin JA, Staymates ME, Benner Jr. BA, Gillen JG. Fabrication of polymer microsphere. Talanta 2008; 76 : 949-55. http://dx.doi.org/10.1016/j.talanta.2008.04.066

[7] Ye N, Wygladacz K, Bakker E. Absorbance characterization. Anal Chim Acta 2007; 596: 195-200. http://dx.doi.org/10.1016/j.aca.2007.06.015

[8] Zhao P, Yan M, Zhang C, Peng R, Ma D, Yu J Determination of glyphosate. Spectrochim Acta A Mol Biomol Spectrosc 2011; 78: 1482-6. http://dx.doi.org/10.1016/j.saa.2011.01.037

[9] Hwang SS, Cho CG, Kim H. Polymer microsphere. Electrochimica Acta 2010; 55: 3236-9. http://dx.doi.org/10.1016/j.electacta.2010.01.044

[10] Jang J, Ha J, Kim S. Fabrication of polyaniline. Macromo Res 2007; 15: 154-9. http://dx.doi.org/10.1007/BF03218767

[11] Li L, Huang Y, Yan G, Liu F, Huang Z, Ma Z. Poly $(3,4-$ ethylenedioxythiophene). Mater Lett 2009; 63: 8-10. http://dx.doi.org/10.1016/j.matlet.2008.08.016

[12] Sui J, Zhang L, Peng H, Travas-Sejdic J, Kilmartin PA. Selfassembly. Nanotechnology 2009 Oct 14; 20(41): 415606. http://dx.doi.org/10.1088/0957-4484/20/41/415606

[13] Liao Y, Li X-G, Kaner RB. Facile Synthesis. ACS Nano 2010; 4: 5193-202. http://dx.doi.org/10.1021/nn101378p

[14] Wang J, Wang J, Wang Z, Zhang F. A Template-Free. Macromol Rapid Commun 2009; 30: 604-8. http://dx.doi.org/10.1002/marc.200800726

[15] Hu Y, Jiang X, Ding Y, Chen Q, Yang CZ. Core-Template. Adv Mater 2004; 16: 933-7. http://dx.doi.org/10.1002/adma.200306579

[16] Gupta B, Chauhan DS, Prakash R. Controlled morphology. Mater Chem Phys 2010; 120: 625-30.

http://dx.doi.org/10.1016/j.matchemphys.2009.12.026 
[17] Atobe M, Ishikawa K, Asami R, Fuchigami T. Size-Controlled. Angew Chem Int Ed 2009; 48: 6069-72. http://dx.doi.org/10.1002/anie.200902062

[18] Liu H, Huang L, Huang Z, Qi G, Kei S, Yutaka H. Preparation of conducting poly $\mathrm{N}$-methylaniline. J Wuhan Univ TechnolMater Sci Ed 2008; 23: 536-40. http://dx.doi.org/10.1007/s11595-006-4536-6

[19] Sanada K, Patil R, Ooyama Y, Yano J, Harima Y. Templatefree. Polym J 2006; 38: 732-6. http://dx.doi.org/10.1295/polymj.PJ2005222

[20] Wang Z, Wang Y, Hu N, Wei L, Chen S, Zhang Y. Polythiophene. J Polym Sci Part Polym Chem 2010; 48: 5265-9. http://dx.doi.org/10.1002/pola.24337

[21] Meier W. Polymer nanocapsules. Chem Soc Rev 2000; 29: 295-303. http://dx.doi.org/10.1039/a809106d

[22] Shenoy SL, Bates WD, Frisch HL, Wnek GE. Role of chain entanglements. Polymer 2005; 46: 3372-84. http://dx.doi.org/10.1016/j.polymer.2005.03.011

[23] Watanabe H, Matsuyama T, Yamamoto H. Experimental. J Electrost 2003; 57: 183-97. http://dx.doi.org/10.1016/S0304-3886(02)00139-0

[24] Harpur IG, Bailey AG, Hashish AH. A design method. J Aerosol Sci 1996; 27: 987-96. http://dx.doi.org/10.1016/0021-8502(96)00044-4
[25] Bock N, Woodruff MA, Hutmacher DW, Dargaville TR. Electrospraying. Polymers 2011; 3: 131-49. http://dx.doi.org/10.3390/polym3010131

[26] Nath SD, Son S, Sadiasa A, Min YK, Lee BT. Preparation. Int J Pharm 2013; Feb 25; 443: 87-94. http://dx.doi.org/10.1016/j.ijpharm.2012.12.037

[27] Hu C, Zhao J, Cui W. Fabrication. J Appl Polym Sci 2013; 128: 3177-83.

http://dx.doi.org/10.1002/app.38383

[28] Zhang Q, Wang L, Wei Z, Wang X, Long S, Yang J. A new simple method. Colloid Polym Sci 2012; 290: 1257-63. http://dx.doi.org/10.1007/s00396-012-2645-7

[29] Liu Y, Wang C, Li M, Lai G, Shen Y. Synthesis and Spectroscopic. Macromolecules 2008; 41: 2045-8. http://dx.doi.org/10.1021/ma702035c

[30] Mancilha FS, DaSilveira Neto BA, Lopes AS, et al. Are Molecular. Eur J Org Chem 2006: 4924-33. http://dx.doi.org/10.1002/ejoc. 200600376

[31] Jaworek A, Sobczyk AT. Electrospraying. J Electrost 2008 ; 66: 197-219. http://dx.doi.org/10.1016/j.elstat.2007.10.001

[32] Ranjith K, Swathi SK, Kumar P, Ramamurthy PC Dithienylcyclopentadienone. Sol Energy Mater Sol Cells 2012; 98: 448-54. http://dx.doi.org/10.1016/j.solmat.2011.11.034 